\title{
Temporal distribution of, and effect of anthropic modifications on, phlebotomine populations in the Chaco Bioregion, Argentina
}

\author{
E. A. SZELA G ${ }^{1,2,3}$, J. R. ROSA ${ }^{1}$, M. G. Q U I N T A A A ${ }^{4,2,3}$ and \\ O. D. $\mathrm{SALOMON} \mathrm{N}^{2,3}$
}

${ }^{1}$ Instituto de Medicina Regional, Universidad Nacional del Nordeste, Resistencia, Chaco, Argentina, ${ }^{2}$ Instituto Nacional de Medicina Tropical, Ministerio de Salud, Puerto Iguazú, Misiones, Argentina, ${ }^{3}$ Consejo Nacional de Investigaciones Científicas y Tecnológicas (CONICET), CABA, Buenos Aires, Argentina and "Instituto Superior de Entomología "Dr. Abraham Willink", Universidad Nacional de Tucumán, San Miguel de Tucumán, Tucumán, Argentina

\begin{abstract}
The Phlebotominae (Diptera: Psychodidae) are insects of medical and veterinary importance, because some species are able to transmit pathogens such as Leishmania spp. In the last 20 years, numerous leishmaniasis outbreaks have been reported in the Chaco Bioregion (Argentina), with an increasing trend of cases associated with periurban transmission. The Chaco Bioregion has two sub-regions according to their climatic and ecological characteristics: the Dry Chaco and the Humid Chaco. In the present study, sandfly captures were performed in both sub-regions, at sites with different levels of anthropic modifications, with the aim of describing differential spatio-temporal patterns of potential tegumentary and visceral leishmaniasis vectors. The captures yielded 3559 sandflies of 14 species. Migonemyia migonei (França) was the prevalent species in the Dry Chaco, whereas Mg. migonei and Nyssomyia neivai (Pinto) were co-dominant in the Humid Chaco. Environmental factors such as degree of anthropic modification and climatic factors were found to modulate both the phlebotomine fauna composition and the diversity and abundance of each species. These factors would increase vector abundances, and thus the transmission risk, during warm months with moderate rainfall, especially in areas with higher anthropic modifications. The co-dominance patterns observed in transitional areas could contribute to the transmission of leishmaniases.
\end{abstract}

Key words. Migonemyia migonei, Nyssomyia neivai, eco-epidemiology, leishmaniasis, vector.

\section{Introduction}

Leishmaniases are parasitic diseases caused by protozoa of the genus Leishmania Ross (Trypanosomatida:Trypanosomatidae), which are transmitted by phlebotomine sandflies. In Argentina, tegumentary leishmaniasis (TL) transmission, which has been known since 1916, presents several 'hot spots' and sporadic outbreaks in nine provinces (the province being the primary sub-national political jurisdiction) of the country where TL is endemic. In these provinces, Leishmania (Viannia) braziliensis (Vianna) has been identified as the main aetiological agent and is considered responsible for transmission of the epidemic (Salomón etal., 2008). In the last 20 years, several TL outbreaks have been reported in different provinces of the Chaco Bioregion, highlighting the increasing trend of cases associated with periurban transmission and so with changes in the location, abundance and diversity of sandfly populations (Salomón et al., 2008; Rosa et al., 2010). 
Studies conducted up to the 1960 s in the Chaco region identified seven sandfly species: Nyssomyia intermedia (syn. Ny. neivai) (Pinto), Evandromyia (Barrettomyia) cortelezzii (Brèthes), Sciopemyia sordellii (Shannon \& Del Ponte), Psathyromyia shannoni (Dyar), Psathyromyia (Psathyromyia) microcephala (syn. Pa. bigeniculata) (Floch \& Abonnenc), Brumptomyia brumpti (Larrousse) and Brumptomyia avellari (Costa Lima) (Bejarano, 1959). It was not until the outbreaks occurred in the 1990s that studies in the region were resumed, expanding the known species with records of Evandromyia (Barrettomyia) sallesi (Galvão \& Coutinho), Lutzomyia longipalpis (Lutz \& Neiva), Micropygomyia (Sauromyia) peresi (Mangabeira), Micropygomyia (Sauromyia) quinquefer (Dyar), Migonemyia (Migonemyia) migonei (França), Pintomyia pessoai (Coutinho \& Barretto) and Pintomyia (Pintomyia) torresi (Le Pont \& Desjeux), with a lack of records of Sc. sordelli since 1959 (Salomón etal., 2008; Rosa etal., 2010). The studies carried out since 2001 suggest that the distribution patterns of sandfly species vary according to the biogeographical region. Hence, the TL transmission pattern and the primary vector species could be expected to vary among regions. In Chaco Province, there may be two different TL transmission patterns according to the diversity and dynamics of sandfly populations with vector competence in the area: (a) western Chaco, a region where $M g$. migone $i$ is the prevalent species and where TL cases are usually scattered in time and space with a mainly sylvatic zoonotic cycle, and (b) eastern Chaco, a region with a higher TL incidence and outbreaks and a peridomestic synanthropic zoonotic cycle, where Ny. neivai is the prevalent species with a high abundance (Salomón et al., 2008).

While the incidence of TL oscillates between epidemic and interepidemic years, that of visceral leishmaniasis (VL) has increased sharply, accompanied by an expansion to new areas. From 2006, when the first human case of VL was described in Posadas City, in the province of Misiones, until 2014, $141 \mathrm{VL}$ cases were reported in four provinces, with Misiones having the highest incidence (Moya etal., 2015). In this province, the disease has been associated with Leishmania infantum (Nicolle)-infected dogs and Lu. longipalpis (primary vector) with urban transmission cycles (Moya et al., 2015). From 2006 to 2013, Lu. longipalpis extended its distribution to the centre and west of the country, including the provinces of Misiones (2006), Corrientes (2008-2009), Chaco, Entre Ríos (2010) and Salta (2013) (Salomón et al., 2011; Gómez Bravo et al., 2013). In 2009, the city of Corrientes reported active transmission of $\mathrm{VL}$ as a result of the continuous presence of Lu. longipalpis, dogs infected with Le. infantum and one autochthonous human case (Salomón et al., 2011). Considering this distribution, the province of Chaco has been highlighted as a vulnerable area for LV transmission, as a consequence of its proximity to Corrientes City and a possible dispersion route of VL to the southwest of the country (Szelag et al., 2014). These findings, in addition to TL transmission having been known since the 1950s, emphasize the importance of identifying localities with a presence and high abundance of potential TL and VL vectors, and of characterizing their variation in time and space so as to establish the transmission risk in periurban and rural localities with different degrees of anthropic modifications. A better understanding of the changes in vectors and risk of both leishmaniases in a transitional area under anthropic pressure, extrapolated at regional level, would contribute to establishing focused surveillance strategies.

\section{Materials and methods}

\section{Study area and sampling sites}

Chaco Province $\left(24^{\circ} 28^{\prime} \mathrm{S}, 58^{\circ} 63^{\prime} \mathrm{W}\right)$, Argentina, belongs to the South American Chaco Biogeographical Region and represents a $99.633-\mathrm{km}^{2}$ area, located at $250 \mathrm{~m}$ above sea level (a.s.l.) on the west side of the province and at $47 \mathrm{~m}$ a.s.l. on the east side of the province. The isohyetal line of $900 \mathrm{~mm}$ divides the province into the eastern Humid Chaco sub-region and the western Dry Chaco sub-region (Fig. 1). The Humid Chaco presents a humid Atlantic rainfall pattern, reaching $1200 \mathrm{~mm} /$ year, with high precipitation in summer and autumn, and is represented by park and savanna biomes. The Dry Chaco sub-region, in contrast, presents a dry and semiarid continental rainfall pattern, reaching $500-800 \mathrm{~mm} /$ year, and is represented by xerophytic hardwood forests. In this region, the humid season is during the summer, whereas the dry season extends over 6 months in winter (Cabrera, 1971). The landscape is a mosaic that changes from the eastern savannas and grasslands to the western thorn forests and open woodlands populated by Quebracho/Algarrobo (Schinopsis, Aspidosperma and Prosopis) and Quebracho/Palo Santo (Schinopsis and Bulnesia) trees, thorny shrubs and cacti (Cabrera, 1971).

With the objectives of representing different degrees of anthropic modification and land use, of identifying the sandfly fauna of each sub-region, and of determining the population distribution pattern in space and time, different sites were selected for sandfly sampling in each sub-region. The criterion for site selection was the 'worst case scenario', which represented an inhabited dwelling with favourable conditions for vector development, soil rich in organic natural or waste material, shady trees, hens or poultry in the peridomicile, and forest patches not less than $100 \mathrm{~m}$ from the dwelling (Salomón et al., 2011).

Dry Chaco sub-region. Captures in the Dry Chaco were carried out at two sites: Fortín Arenales $\left(\mathrm{DC}_{1}\right)\left(24^{\circ} 58^{\prime} 7.5^{\prime \prime}\right.$ $\left.\mathrm{S}, 61^{\circ} 21^{\prime} 1.1^{\prime \prime} \mathrm{W}\right)$ and Los Pozos $\left(\mathrm{DC}_{2}\right)\left(24^{\circ} 54^{\prime} 13.2^{\prime \prime} \mathrm{S}\right.$, $\left.61^{\circ} 22^{\prime} 3.9^{\prime \prime} \mathrm{W}\right)$, within the municipality of Misión Nueva Pompeya. At each site, two houses with historical records of TL or active TL human cases were selected. The forests in the areas surrounding the two sites showed severe deforestation and anthropic modifications. These modifications were more severe in $\mathrm{DC}_{1}$ as a consequence of the constant grazing pressure exerted by goats and cows, which left almost bare soil. $\mathrm{DC}_{2}$ had less severe modifications and more conserved forest patches (without signs of grazing pressure, felling or burning).

Humid Chaco sub-region. Captures in the Humid Chaco were carried out in three localities with a history of TL cases: (a)

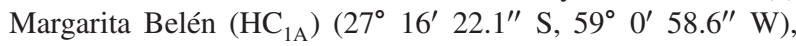




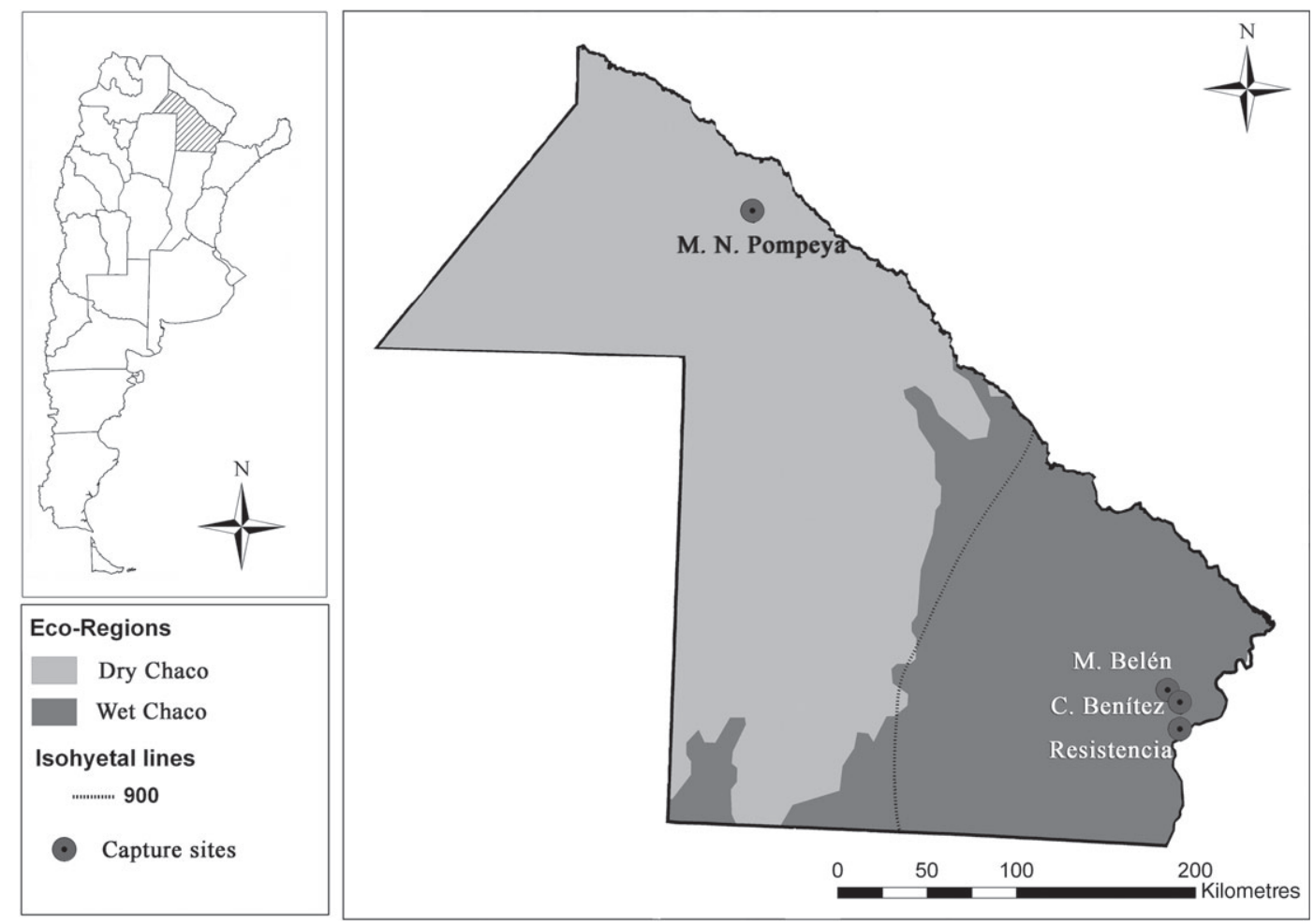

Fig. 1. Geographical location of study areas, Misión Nueva Pompeya, Margarita Belén, Colonia Benítez and Resistencia, in the Chaco biogeographical sub-regions of Chaco Province, Argentina.

on a farm dedicated to livestock and with a history of human TL (Fig. 1); (b) Resistencia $\left(\mathrm{HC}_{1 \mathrm{~B}}\right)\left(27^{\circ} 26^{\prime} 25.6^{\prime \prime} \mathrm{S}, 58^{\circ} 54^{\prime}\right.$ $\left.59.8^{\prime \prime} \mathrm{W}\right)$, in a periurban area with active urbanization and a human TL history (Fig. 1); and (c) Colonia Benítez $\left(\mathrm{HC}_{2}\right)$ $\left(27^{\circ} 19^{\prime} 16.8^{\prime \prime} \mathrm{S}, 58^{\circ} 59^{\prime} 53.3^{\prime \prime} \mathrm{W}\right)$, within a municipality for which cases had been reported, in a house with a henhouse, without a TL history, located on the east margin of National Route 11 (Fig. 1). $\mathrm{HC}_{1 \mathrm{~A}}$ and $\mathrm{HC}_{1 \mathrm{~B}}$ are both considered highly modified environments, presenting the same signs of anthropic modification, but different land use. The landscape in $\mathrm{HC}_{1 \mathrm{~A}}$ is a mosaic that changes from the riparian gallery of the Carolí creek to forest relicts and deforested areas of grassland, with signs of anthropic modifications. $\mathrm{HC}_{1 \mathrm{~B}}$ corresponds to a farm dedicated to agriculture, with forest patches near the house that had suffered edge deforestation to extend the cropping area. $\mathrm{HC}_{2}$ was considered less modified, with forest patches and the riparian gallery of the Negro river being more conserved (no grazing pressure, trampling, felling or burning) than the other two sites.

\section{Sandfly captures}

Adult sandflies were captured by installing Centers for Disease Control and Prevention (CDC) miniature light traps (Sudia \& Chamberlain, 1962) $1.5 \mathrm{~m}$ above the ground, which were active for $12 \mathrm{~h}$ (from $7 \mathrm{pm}$ to $7 \mathrm{am}$ ). In each house, the traps were placed in: (a) the domicile (indoors or on the veranda); (b) the peridomicile (in pens or animal resting places, near the house); (c) the extradomicile (forest patches, not less than $100 \mathrm{~m}$ from the house). In the Dry Chaco, captures were performed on one night every month from November 2006 to December 2008, whereas in the Humid Chaco, captures were performed on one night every month from October 2010 to September 2012. In the Dry Chaco, because of logistical restrictions related to heavy rainfalls in 2008 , the captures were discontinuous, totalling 24 samples in $\mathrm{DC}_{1}$ (1728 h/trap) and 14 samples in $\mathrm{DC}_{2}$ (1008 h/trap).

\section{Weather variables}

Relative humidity ( $\mathrm{RH}$ ), average temperature (av. T), minimum temperature (min. T), maximum temperature (max. T) and cumulative precipitation (rainfall) were recorded monthly. In the Humid Chaco, monthly average records were obtained from the weather stations of the Instituto Nacional de Tecnología Agropecuaria (INTA)-Colonia Benítez and Universidad Nacional del Nordeste, and punctual records for each capture were obtained with a digital $\mathrm{max} / \mathrm{min}$ thermohygrometer (Hygrotherm, TFA ${ }^{\circledR}$, Wertheim, Germany). Because there are no meteorological stations near the sampling sites of Dry Chaco (the closest station is $250 \mathrm{~km}$ away), only punctual records were obtained using a max/min thermometer from the start to the end of each sampling period, and monthly cumulative precipitation was obtained from Misión Nueva Pompeya Police Station. 


\section{Sandfly identification}

The specimens were clarified according to Forattini (1973) and mounted in Canada balsam, and identified following the taxonomic keys of Galati (2003). As a consequence of the sympatry of Ev. cortelezzii and Ev. sallesi in the region (Rosa etal., 2012) and the impossibility of differentiating females of these species by morphological characteristics, they are cited in this text as cortelezzii complex. For diversity analysis, females are treated as a single species (cortelezzii complex), whereas males are differentiated by species.

\section{Data analysis}

The species richness $(S)$, Shannon-Wiener diversity index $\left(H^{\prime}\right)$ and evenness of Pielou $\left(J^{\prime}\right)$ were used to measure the structure and diversity of the communities. The chi-squared test $\left(\chi^{2}\right)$ was used to evaluate variation of species frequency by ecotope and sampling site and differences in meteorological values between sub-regions and years. The seasonal and monthly variation of sandfly abundance was referred to as its population dynamics. As a consequence of the difference in sampling efforts in the two regions, in order to minimize this difference for comparative purposes, a seasonal average abundance was computed for each species per region, estimated as follows: $\sum$ specimens $_{\text {months } i-n} / n$, where $n$ is the number of months per season; only months with effective captures were computed. In addition, for the monthly variation in the Dry Chaco, a monthly average was computed between the monthly effective captures to estimate the annual variation as a consequence of the interrupted captures. The correlation between the abundance of each epidemiologically relevant species with monthly average meteorological variables [obtained from weather stations (a) and the specific records for each capture (b)] was estimated using the Spearman correlation index $\left(r_{\mathrm{S}}\right)$.

\section{Results}

Fourteen sandfly species were recorded: $\mathrm{Br}$. avellari, $\mathrm{Br}$. brumpti, Evandromyia (Aldamyia) aldafalcaoae (Santos, Andrade Filho \& Honer), Evandromyia (Aldamyia) termitophila (Martins, Falcão \& Silva), Ev. cortelezzii, Ev. sallesi, Evandromyia (Barrettomyia) corumbaensis (Galati, Nunes, Oshiro \& Rego), Mi. peresi, Mi. quinquefer, Mg. migonei, $\mathrm{Ny}$. neivai, Pi. torresi, Pa. bigeniculata and Sc. sordellii.

A total of 2059 sandflies were captured in the Dry Chaco, whereas 1500 sandflies were captured in the Humid Chaco (Table 1). The two sub-regions showed different fauna compositions and species relative abundances (Table 1). In the Dry Chaco, Mg. migonei was the predominant species, followed by the cortelezzii complex, whereas in the Humid Chaco, a co-dominance of $\mathrm{Mg}$. migonei and $\mathrm{Ny}$. neivai was observed [no statistically significant differences were observed between the two in their distributions by locality $\left(\chi^{2}=2.671 ; P=0.26\right.$; $d f=2)$ ], followed by the cortelezzii complex. The remaining species represented $<20 \%$ of the total in each sub-region (Table 1).
The Dry Chaco and the Humid Chaco showed the same species richness, but the Dry Chaco showed higher sandfly abundance, diversity and equitability. Sites with evident anthropic modifications such as $\mathrm{HC}_{1 \mathrm{~A}}$ and $\mathrm{DC}_{1}$ showed higher sandfly abundance and species richness, but lower diversity and equitability (Table 1). In contrast, the less modified sites, $\mathrm{HC}_{2}$ and $\mathrm{DC}_{2}$, showed greater diversity and equitability but low abundances (Table 1). However, $\mathrm{HC}_{1 \mathrm{~A}}$ and $\mathrm{HC}_{1 \mathrm{~B}}$ showed no differences in the abundance of captured sandflies $\left(\chi^{2}=2.015\right.$; $P=0.15 ; d f=1)$, although $\mathrm{HC}_{1 \mathrm{~B}}$ had less species richness but higher diversity and equitability (Table 1).

The ecotope distribution showed significant differences in the abundances of the species studied between the two sub-regions (Table 1). In the Humid Chaco, most of the species predominated in the extradomicile, except for Ev. corumbaensis and Ev. aldafalcaoae, whose single specimens were captured in the peridomicile (Table 1). In the Dry Chaco, most of the species predominated in the peridomicile, except for Ev. termitophila, with a single specimen captured in the domicile. Pintomyia torresi and $M i$. quinquefer were predominant in the extradomicile and $N y$. neivai was captured at low frequency in the domicile and extradomicile. The cortelezzii complex showed the same distribution in both sub-regions, with higher abundance in the extradomicile (Table 1). Comparing the ecotope distributions between sites, $\mathrm{Mg}$. migonei showed the same trend in each site as the general tendency of the sub-region. However, in $\mathrm{HC}_{2}, N y$. neivai presented a higher abundance in the peridomicile, contrary to the extradomicile predominance recorded for $\mathrm{HC}_{1 \mathrm{~A}}$ and $\mathrm{HC}_{1 \mathrm{~B}}$ (Table 1).

The presence of $M g$. migonei, $N y$. neivai and the cortelezzii complex in the domicile of both sub-regions should be highlighted because of its epidemiological implications. In contrast, Ev. corumbaensis, Ev. termitophila and Mi. quinquefer were captured only in the domicile of the Dry Chaco (Table 1).

The seasonal average abundance of sandflies captured in the Humid Chaco showed an evident predominance in summer followed by spring/autumn and winter, whereas that in the Dry Chaco was higher in spring followed by summer and autumn, with only a few records of $\mathrm{Mg}$. migonei in winter (Table 2). There were no significant differences in monthly temperature variation between years or regions in the studied period, whereas significant differences were found for cumulative rainfall between regions $\left(\chi^{2}=274.823 ; P<0.0001 ; d f=11\right)$ and years $\left(\chi^{2}=526.272 ; P<0.0001 ; d f=11\right)$. In the Humid Chaco, Spearman's index showed a high correlation between monthly abundances of $N y$. neivai and $M g$. migonei $\left(r_{\mathrm{s}}=0.92\right.$; $P<0.001)$. Both species showed greater abundance during spring-summer, with higher peaks in November-December, and variations between years related to a second summer peak in February, and an autumn peak in April-May (Fig. 2A,B). The cortelezzii complex also showed different distributions in the two years, with the highest abundance in summer in one year and autumn in the other (Fig. 2C).

In the Dry Chaco, despite the differences in the sampling effort, we observed that both $\mathrm{Mg}$. migonei and the cortelezzii complex showed monthly variation, with abundance peaks in January, March and November, the November peak being clearly higher than the others [more than two standard deviation (SD) units from the annual mean $(\mathrm{SD}=204.15 ; \bar{X}=127.54)]$ (Fig. 3). 


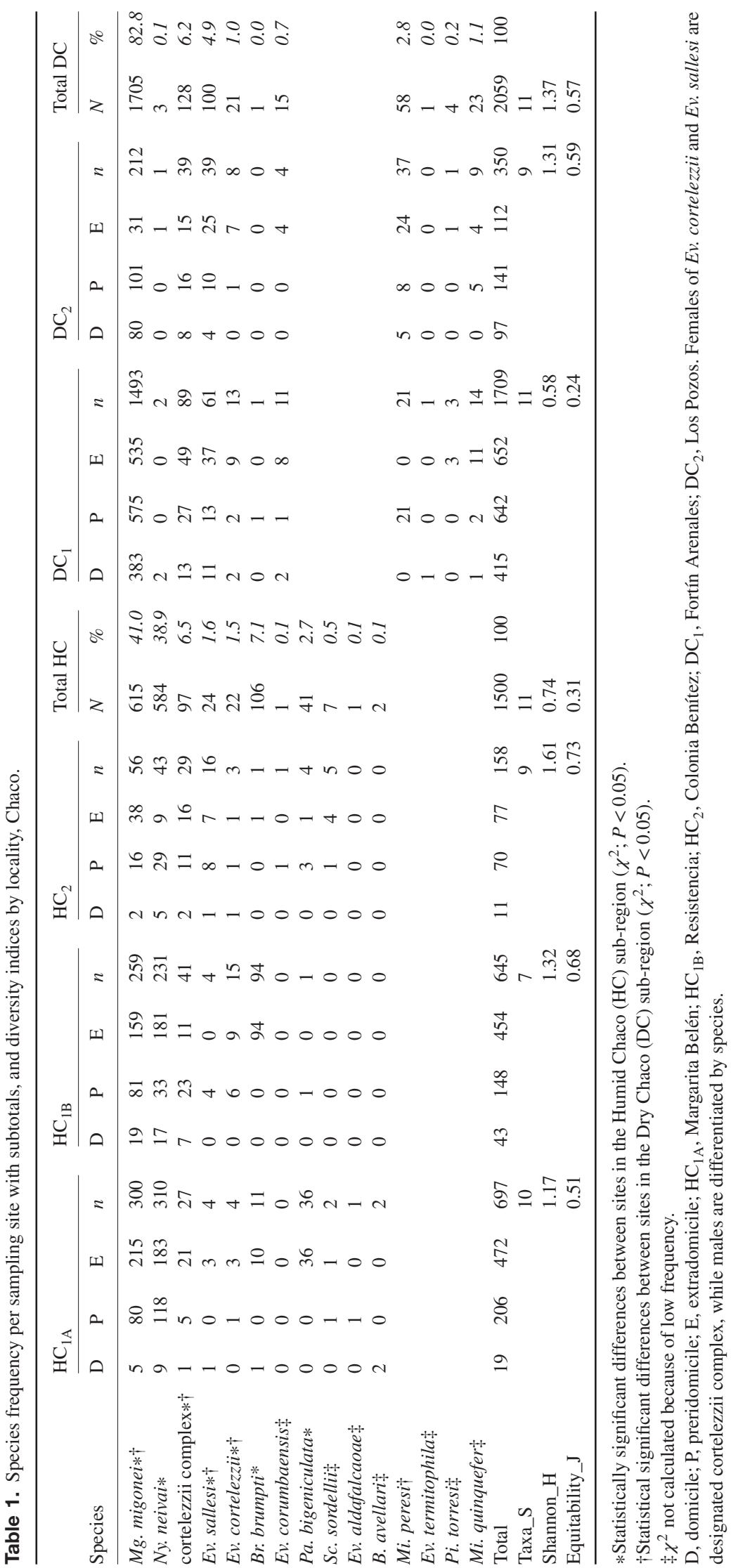


Table 2. Seasonal average abundance of sandflies, by species and study region in Chaco, Argentina.

\begin{tabular}{|c|c|c|c|c|c|c|c|c|}
\hline \multirow[b]{2}{*}{ Species } & \multicolumn{4}{|c|}{ Humid Chaco } & \multicolumn{4}{|l|}{ Dry Chaco } \\
\hline & Spring & Summer & Autumn & Winter & Spring & Summer & Autumn & Winter \\
\hline Mg. migonei & $5.83(7.3)$ & $20.05(15.79)$ & $6.72(4.4)$ & $1.55(2.4)$ & $202.75(315.9)$ & $70.25(37.2)$ & $66(98.3)$ & $0.33(0.3)$ \\
\hline Ny. neivai & $9.44(13.9)$ & $16.5(13.4)$ & $5.55(7.0)$ & $0.94(1.1)$ & $0.25(0.5)$ & 0.00 & $0.33(0.3)$ & 0.00 \\
\hline cortelezzii complex & $0.89(0.8)$ & $1.44(1.6)$ & $2.83(2.2)$ & $0.22(0.4)$ & $14.25(14.1)$ & $6.75(3.3)$ & $4.67(4.2)$ & 0.00 \\
\hline Ev. cortelezzii & $0.11(0.2)$ & $0.39(0.8)$ & $0.72(0.9)$ & 0.00 & $1.50(1.7)$ & $1.00(1.1)$ & $1.33(1.9)$ & 0.00 \\
\hline Ev. sallesi & $0.05(0.2)$ & $0.61(0.5)$ & $0.55(0.6)$ & $0.11(0.2)$ & $10.25(10.6)$ & $6.00(6.1)$ & $2.33(2.8)$ & 0.00 \\
\hline Ev. corumbaensis & 0.00 & 0.00 & $1.16(0.4)$ & 0.00 & $1.50(1.3)$ & $1.50(2.3)$ & $0.33(0.3)$ & 0.00 \\
\hline Br. brumpti & $5.44(12.7)$ & $0.33(0.4)$ & $0.05(0.1)$ & $0.05(0.1)$ & $0.25(0.5)$ & 0.00 & 0.00 & 0.00 \\
\hline Pa. bigeniculata & 0.00 & $1.83(2.4)$ & $0.33(0.5)$ & $0.11(0.2)$ & & & & \\
\hline Sc. sordelli & 0.00 & $0.11(0.3)$ & $0.28(0.3)$ & 0.00 & & & & \\
\hline Ev. aldafalcaoae & 0.00 & $0.05(0.1)$ & 0.00 & 0.00 & & & & \\
\hline Br. avellari & 0.00 & 0.00 & $0.11(0.3)$ & 0.00 & & & & \\
\hline Mi. quinquefer & & & & & $1.50(2.4)$ & $1.00(1.4)$ & $1.50(2.6)$ & 0.00 \\
\hline Mi. peresi & & & & & $2.00(4)$ & $2.12(3.9)$ & $5.50(5.1)$ & 0.00 \\
\hline Pi. torresi & & & & & $0.25(0.5)$ & $0.25(0.5)$ & $0.17(0.3)$ & 0.00 \\
\hline Ev. termitophila & & & & & $0.25(0.5)$ & 0.00 & 0.00 & 0.00 \\
\hline Total & 21.78 & 41.31 & 18.30 & 2.98 & 234.75 & 88.88 & 82.17 & 0.33 \\
\hline
\end{tabular}

Females of Ev. cortelezzii and Ev. sallesi are designated cortelezzii complex, while males are differentiated by species.

Values are mean (standard deviation).

In the period May to August 2008, no phlebotomines were caught, except for one $\mathrm{Mg}$. migonei male, caught in the domicile of $\mathrm{DC}_{1}$ in July 2008 (Fig. 3).

In the Humid Chaco, Spearman's correlation index between the monthly average abundances of $\mathrm{Mg}$. migonei, $\mathrm{Ny}$. neivai and the cortelezzii complex and the monthly average and punctual meteorological records showed a higher correlation with temperature than with precipitation and no correlation $\left(r_{\mathrm{s}} ; P>0.05\right)$ with RH (Table 3). Although there were variations between the correlations of sandfly abundance and the meteorological monthly average and punctual records, the same trend was observed for the three species. In the Dry Chaco, both $M g$. migonei and the cortelezzii complex showed a higher correlation with monthly cumulative precipitation, followed by a correlation with the minimum temperature for $\mathrm{Mg}$. migonei and with average temperature for the cortelezzii complex (Table 3).

\section{Discussion}

The fauna composition recorded in this work is similar to that previously recorded in the region (Salomón et al., 2008; Rosa et al., 2010). However, during this study, the presence of Ev. aldafalcaoae, Ev. corumbaensis and Ev. termitophila was recorded for the first time in Argentina, and individuals of the species previously recorded in Chaco Province as $\mathrm{Pa}$. shannoni and $P a$. microcephala were assigned here to $P a$. bigeniculata (Szelag etal., 2016). Also, the presence of Sc. sordellii was recorded again in the Chaco region following a lack of records since the 1950s (Bejarano, 1959). The species composition recorded in the Chaco region, especially in the Dry Chaco, is similar to that recorded in the Brazilian and Bolivian Chaco Domain, mainly in the Cerrado and Caatinga regions of Brazil (Galati, 2016). This distribution is consistent with the fact that the landscape and flora composition of both biogeographical regions are considered to be very similar to those of the Chaco region in Argentina (Cabrera, 1971).

The high abundance of $\mathrm{Ny}$. neivai and $\mathrm{Mg}$. migonei in the Humid Chaco and the predominance of $\mathrm{Mg}$. migone $i$ with scarce records of Ny. neivai in the Dry Chaco have previously been recorded in Chaco Province (Salomón et al., 2008; Rosa et al., 2010). As described in the Introduction, it was hypothesized that, in the Argentinean Chaco, there are two main diversity patterns of sandfly captures (Salomón et al., 2008). The results obtained in the present study suggest a third type of distribution related to rural and periurban areas of the Humid Chaco, associated with forest patches with a high degree of anthropic modification, where $\mathrm{Mg}$. migonei and $\mathrm{Ny}$. neivai showed a co-dominance with an $\mathrm{Ny}$. neivai:Mg. migonei ratio of 0.9 $(n=1199)$, in contrast to the higher prevalence of $N y$. neivai recorded in other areas of the Humid Chaco in Argentina (Salomón et al., 2008). However, comparison of previous results obtained in the same area of Resistencia with a similar capture effort and traps during 2001-2003 (Salomón et al., 2008) and those obtained in 2010-2012 suggests that the co-dominance has tended to increase together with the progress of deforestation and anthropic modifications in the area, although the possibility of effects of climate variations between sampling years cannot be discounted.

The differences in sampling effort and periods do not allow conclusive comparisons. However, these exploratory results suggest that there could be differences between sub-regions and between sites of each sub-region in sandfly abundance, species dominance and diversity. This variation seems to be related to the degree of anthropic modification, showing an increased abundance and dominance of suspected vector species such as $M g$. migonei and Ny. neivai in areas where anthropic modifications are greater. This has also previously been observed in the provinces of Formosa (Salomón et al., 2002) and Salta 
(A)
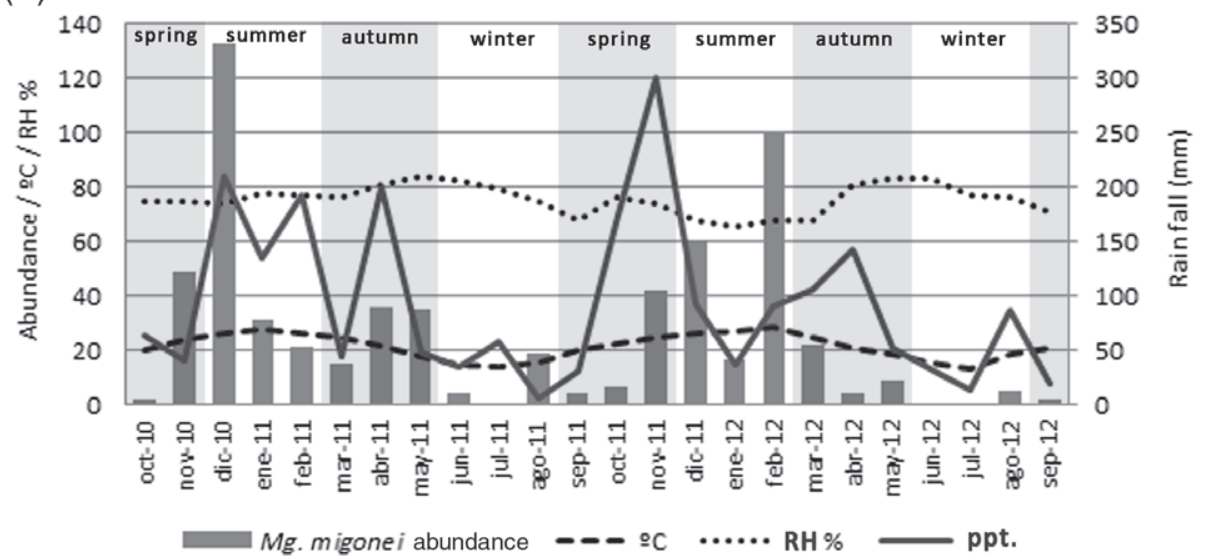

(B)
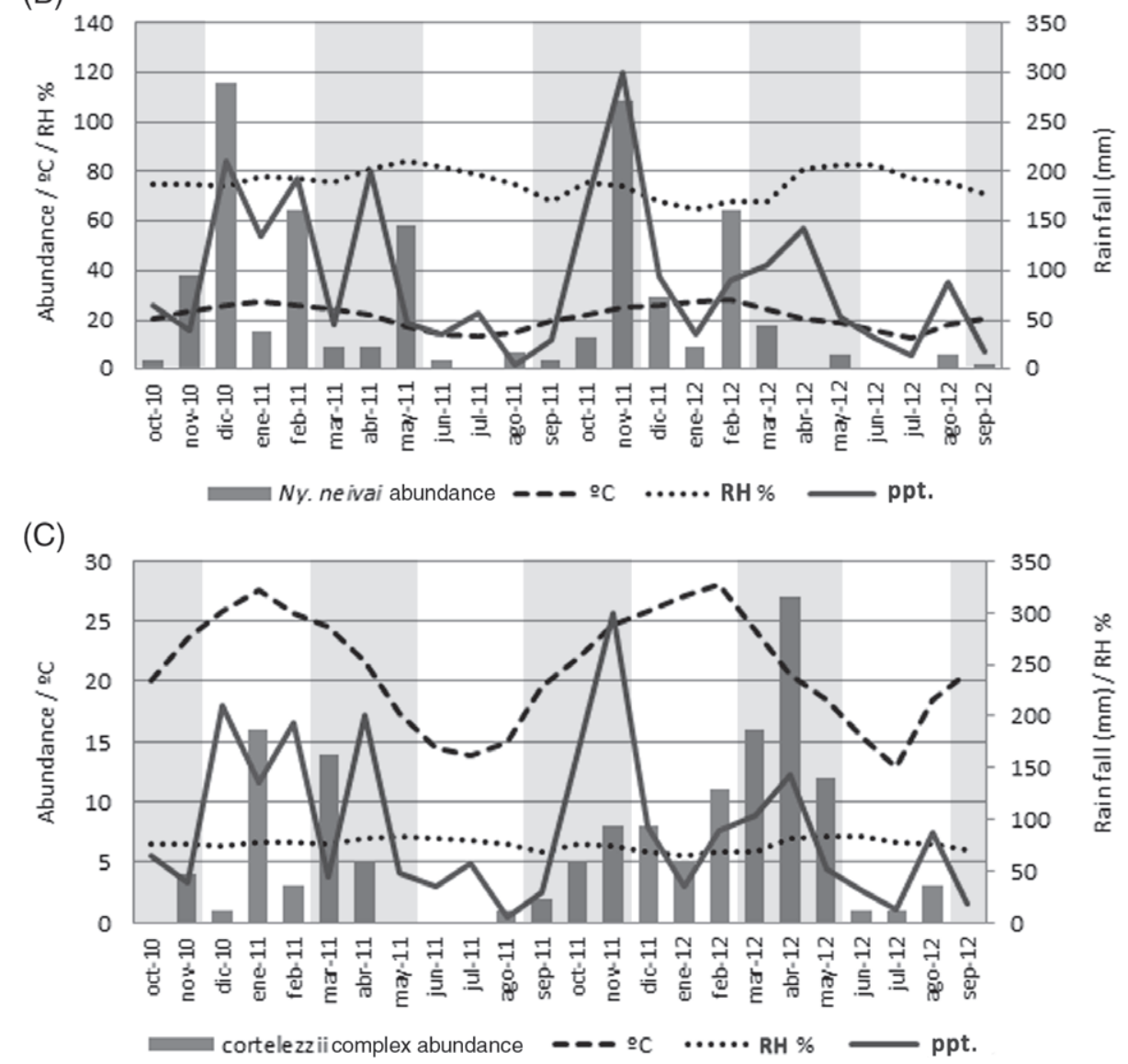

Fig. 2. Monthly abundance of sandflies caught in the Humid Chaco region of Chaco, Argentina, in the period October 2010 to September 2012 for (A) Migonemyia migonei, (B) Nyssomyia neivai and (C) the cortelezzii complex; and variation of average monthly temperature $\left({ }^{\circ} \mathrm{C}\right)$, average monthly relative humidity $(\mathrm{RH})$ and accumulated monthly precipitation (ppt.).

(Quintana etal., 2012), Argentina, where an association of these species with highly modified environments and a possible increase in population abundance when these environments were disturbed were found.

The results suggest that sandfly populations in the Chaco region are closely linked to the presence of forest patches and barnyard animals in the peridomicile, which are probable natural breeding and resting sites (Parras et al., 2012). However, some species such as Mg. migonei, Ny. neivai and the cortelezzii complex may visit the domicile only occasionally in search of blood-feeding opportunities, as they apparently have not achieved complete domestication or domicile predominance as 


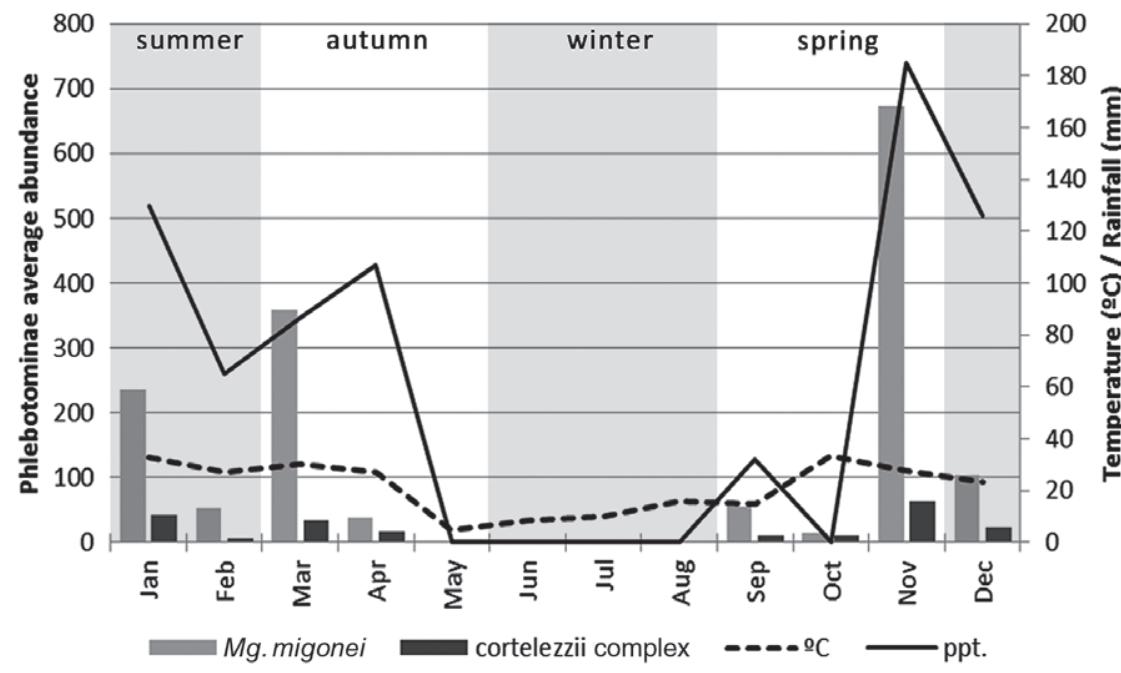

Fig. 3. Average monthly abundance of Migonemyia migonei and the cortelezzii complex captured in the Dry Chaco sub-region of Chaco, Argentina, in the period November 2006 to December 2008, with average temperature during the capture $\left({ }^{\circ} \mathrm{C}\right)$ and cumulative monthly rainfall.

Table 3. Spearman's correlation index of sandfly abundance by species and region for (A) average monthly meteorological variables, obtained from meteorological stations, and (B) punctual records during captures, obtained with a digital thermohygrometer.

\begin{tabular}{|c|c|c|c|c|c|c|c|c|c|}
\hline Species & Av. T (A) & Av. T (B) & Max. T (A) & Max. T (B) & Min. T (A) & $\operatorname{Min} T(B)$ & $\mathrm{RH}(\%)(\mathrm{A})$ & $\mathrm{RH}(\%)(\mathrm{B})$ & Rainfall \\
\hline Mg. migone $\mathrm{HC}$ & $0.714 *$ & $0.687 *$ & $0.696 *$ & $0.642 *$ & $0.704 *$ & $0.561 *$ & -0.330 & -0.115 & $0.532 *$ \\
\hline Mg. migonei DC & - & $0.650 *$ & - & $0.610 *$ & - & $0.660 *$ & - & - & $0.880 *$ \\
\hline Ny. neivai $\mathrm{HC}$ & $0.721 *$ & $0.697 *$ & $0.710 *$ & $0.641 *$ & $0.750 *$ & $0.613 *$ & -0.339 & -0.061 & $0.575 *$ \\
\hline cort. comp. HC & $0.605 *$ & $0.661 *$ & $0.595 *$ & $0.548 *$ & $0.590 *$ & $0.615 *$ & -0.168 & -0.110 & $0.463 *$ \\
\hline cort. comp. DC & - & $0.750 *$ & - & $0.730 *$ & - & $0.730 *$ & - & - & $0.910 *$ \\
\hline
\end{tabular}

*Statistically significant correlation $\left(r_{\mathrm{s}} ; P<0.05\right)$.

HC, Humid Chaco; DC, Dry Chaco; Av. T, average temperature; Max. T, maximum temperature; Min T,minimum temperature; RH, relative humidity; rainfall, monthly cumulative precipitation; cort. comp, cortelezzii complex.

in the Yungas region of Argentina and some states of Brazil (Córdoba-Lanús \& Salomón, 2002; Meneses et al., 2002; Cruz et al., 2012). Further, regarding the variation between ecotopes and sites, the results suggest that $\mathrm{Mg}$. migonei is less affected by slight changes in the degree of anthropic modification of the forest, while the low frequency of $N y$. neivai in the less modified forest of the Humid Chaco suggests that this species is more sensitive to these changes.

The monthly and seasonal variation of sandfly fauna in the studied periods showed that, in the humid areas of Chaco Province, the risk of human-vector contact would be present throughout the year and would be highest during spring-summer, although the summer-spring peaks could be interrupted by the short, intense rainy seasons, as observed in Tucumán Province (Córdoba-Lanús \& Salomón, 2002). In the dry areas of the province, the risk would be restricted to temperate and humid months such as January, March and November. The monthly abundance distribution between years varied, in agreement with that reported for $N y$. neivai in the province of Salta, where this species has annual bimodal and trimodal patterns according to the rainy periods (Salomón et al., 2004). These hypotheses were supported by the correlation indexes, suggesting that the monthly fluctuation and high abundance peaks would be conditioned by rainfall in dry and warm climates and that temperature would be the critical factor in humid areas, as in the Yungas and Paranaense Bioregions of
Argentina (Salomón et al., 2004; Quintana et al., 2010; Fernández et al., 2012). However, this increasing tendency related to high temperature in humid areas would be conditioned by periods of heavy rain, which probably affect the immature stages of sandflies by producing soil leaching (Salomón et al., 2004).

The presence of $\mathrm{Ny}$. neivai and $\mathrm{Mg}$. migonei is noteworthy, because these species have usually been incriminated as vectors of Le. braziliensis in Brazil (Rangel \& Lainson, 2003), and, as a consequence of the epidemiological nexus and natural infection, have been considered probable vectors in Argentina (Salomón etal., 2008). Migonemyia migonei has also been incriminated as a permissive vector of Le. infantum (Moya et al., 2015; Guimarães et al., 2016). Thus, the epidemiological risk associated with the presence of these species is highlighted, although their specific role in transmission must still be verified.

Micropigomyia quinquefer and the cortelezzii complex have previously been found naturally infected with Leishmania sp. in Argentina (Salomón et al., 2009; Rosa et al., 2012). In addition, the cortelezzii complex has been considered as a probable vector of TL in Argentina as a consequence of its high ecological consistency with transmission in the country. It should also be noted that Ev. cortelezzii and Ev. termitophila have been found naturally infected with Le. infantum DNA (Carvalho et al., 2008; Saraiva et al., 2010), and Sc. sordellii with Le. braziliensis DNA in Brazil (Lana etal., 2015), although their vector capacity is still unknown. 
It should also be highlighted that the incipient colonization by Lu. longipalpis of the city of Resistencia recorded in 2010 (Salomón et al., 2011), with low numbers of records in $\mathrm{HC}_{1 \mathrm{~B}}$ in May 2010 (data not shown), was not followed by the continuous establishment of vector populations (Szelag et al., 2014). The absence of $L u$. longipalpis during subsequent years in $\mathrm{HC}_{1 \mathrm{~B}}$ reinforces the hypothesis of an interrupted expansion of $L u$. longipalpis populations in the Chaco region, which could be attributable to weather conditions (very low winter minimum temperature in 2010) or environmental conditions, which limited continuous colonization or spread to other sites in the city and the province.

In conclusion, the data presented herein can be considered as exploratory approximations due to the temporal constraints of the study, but they provide a basis from which to develop further studies and to revalidate the assumptions presented herein. The results suggest that the presence of suspected TL and VL vectors such as $N y$. neivai, $M g$. migonei and the cortelezzii complex in domestic environments close to forest patches would represent a risk factor in the region because it increases the probability of human-vector-reservoir contact. The increase in these species in warm months with moderate rainfall (spring and summer) should be considered in the design of preventive surveillance or intervention. Further, regarding site selection for such surveillance or intervention design, the variation in microscale (ecotope) and mesoscale (locality) vector abundance seems to be modulated by environmental anthropization, as the abundance and predominance of $\mathrm{Ny}$. neiviai and $\mathrm{Mg}$. migonei increased in highly modified areas, as did the epidemiological human-vector contact risk. Moreover, the variations in species composition and population abundance at the macroscale (biogeographical sub-regions) seemed to be affected by the ecological and climatic variation observed between dry and humid areas, thus representing different scenarios that should be considered. Also, the two previously described patterns of species distribution for the Chaco Province were associated with the landscape but also with humidity and climate variables (Salomón et al., 2008). Therefore, in the third scenario described here, the dominance or co-dominance of species could be a dynamic transitional pattern that fluctuates between years. This fluctuations, may be determined by annual weather conditions (certain conditions favouring one species over the other), or by with the microhabitat distribution in the environment, for example in terms of ecotones, domestic-forest borders, and the location of animal dwellings. The temporal and spatial selection criteria of sentinel sites for surveillance based on these kinds of exploratory studies will allow the sensitivity of early alert systems to be increased, but will also provide information on phlebotomine changes during environmental interventions for predictive purposes.

\section{Acknowledgements}

The authors would like to thank collaborators at the Misión Nueva Pompeya Hospital, Matias Ariel Parras for collaboration in the field and laboratory, and the families that allowed us into their homes. This work was supported by the Roemmers Argentinean Foundation, the Consejo Nacional de
Investigaciones Científicas y Técnicas (CONICET) and BID PICT 12-2842.s.

The authors declare that they have no conflict of interest.

\section{References}

Bejarano, J.F.R. (1959) Complejo patógeno de la leishmaniasis en la republica Argentina. Primeras Jornadas Entoepidemiológicas Argentinas (ed. by J.R. Bejarano, E. De Ponte \& R. Orfila), pp. 805-832. La Prensa Médica Argentina, Buenos Aires.

Cabrera, A.L. (1971) Fitogeografía de la republica Argentina. Boletín de la Sociedad Argentina de Botánica, 14, 1-25.

Carvalho, G.M.L., Filho, J.D.A., Falcão, A.L., Rocha Lima, A.C.V.M. \& Gontijo, C.M.F. (2008) Naturally infected Lutzomyia sand flies in a Leishmania -Endemic area of Brazil. Vector-Borne and Zoonotic Diseases, 8, 407-414. https://doi.org/10.1089/vbz.2007.0180.

Córdoba-Lanús, E. \& Salomón, O.D. (2002) Phlebotominae fauna in the province of Tucumán, Argentina. Revista do Instituto de Medicina Tropical de São Paulo, 44, 23-27. https://doi.org/10.1590/S003646652002000100005.

Cruz, M.F.R., Galati, E.A.B. \& Cruz, C.F.R. (2012) Ecological aspects of the sandfly fauna (Diptera, Psychodidae) in an American cutaneous leishmaniasis endemic area under the influence of hydroelectric plants in Paranapanema river, State of Paraná, Brazil. Revista da Sociedade Brasileira de Medicina Tropical, 45, 430-436. https://doi.org/10 .1590/S0037-86822012000400003.

Fernández, M.S., Lestani, E.A., Cavia, R. \& Salomón, O.D. (2012) Phlebotominae fauna in a recent deforested area with American Tegumentary Leishmaniasis transmission (Puerto Iguazú, Misiones, Argentina): seasonal distribution in domestic and peridomestic environments. Acta Tropica, 122, 16-23. https://doi.org/10.1016/j .actatropica.2011.11.006.

Forattini, O.P. (1973) . Entomologia médica. Psychodidae, Phlebotominae, Leishmanioses, Bartonelose. Edgard Blücher, São Paulo.

Galati, E.A.B. (2003) Morfologia, terminologia de adultos e identificação dos táxons da América. Flebotomíneos do Brasil (ed. by E.F. Rangel \& R. Lainson), pp. 53-175. Fiocruz, Rio de Janeiro.

Galati, E.A.B. (2016) . Phlebotominae (Diptera, Psychodidae) classifcação, morfologia, terminologia e identificação de adultos - APOSTILA. Faculdade de Saúde Pública Universidade de São Paulo, São Paulo, Brasil. http://www.fsp.usp.br/egalati/ApostilaPhlebotominae_ 2016_VOL_I.pdf [accessed on 1 December 2016].

Gómez Bravo, A., Quintana, M.G., Abril, M. \& Salomon, O.D. (2013) The first record of Lutzomyia longipalpis in the Argentine northwest. Memórias do Instituto Oswaldo Cruz, 108, 1071-1073. https://doi .org/10.1590/0074-0276130358.

Guimarães, V.C.F.V., Pruzinova, K., Sadlova, J. et al. (2016) Lutzomyia migonei is a permissive vector competent for Leishmania infantum. Parasites \& Vectors, 9, 159. https://doi.org/10.1186/s13071-0161444-2.

Lana, R.S., Michalsky, É.M., Fortes-Dias, C.L. et al. (2015) Phlebotomine sand fly Fauna and Leishmania infection in the vicinity of the Serra do Cipó National Park, a natural Brazilian heritage site. BioMed Research International, 2015, 1-9. https://doi.org/10.1155/ 2015/385493.

Meneses, C.R.V., Azevedo, A.C.R., da Costa, S.M., Costa, W.A. \& Rangel, E.F. (2002) Ecology of American cutaneous leishmaniasis in the state of Rio de Janeiro, Brazil. Journal of Vector Ecology, 27, 207-214.

Moya, S.M., Giuliani, M.G., Manteca Acosta, M., Salomón, O.D. \& Liotta, D.J. (2015) First description of Migonemyia migonei (França) 
and Nyssomyia whitmani (Antunes \& Coutinho) (Psychodidae: Phlebotominae) natural infected by Leishmania infantum in Argentina. Acta Tropica, 152, 181-184.

Parras, M.A., Rosa, J.R., Szelag, E.A. \& Salomón, O.D. (2012) Identification of the natural breeding sites of sandflies (Diptera: Psychodidae: Phlebotominae), potential vectors of leishmaniasis, in the province of Chaco, Argentina. Memorias do Instituto Oswaldo Cruz, 107, 550-552. https://doi.org/10.1590/S0074-02762012000400018.

Quintana, M.G., Salomón, O.D. \& De Grosso, M.S.L. (2010) Distribution of Phlebotomine sand flies (Diptera: Psychodidae) in a primary Forest-crop Interface, Salta, Argentina. Journal of Medical Entomology, 47, 1003-1010. https://doi.org/10.1603/ME09072.

Quintana, M.G., Fernández, M.S. \& Salomón, O.D. (2012) Distribution and abundance of Phlebotominae, vectors of Leishmaniasis, in Argentina: spatial and temporal analysis at different scales. Journal of Tropical Medicine, 2012, 1-16. https://doi.org/10.1155/2012/ 652803.

Rangel, E.F. \& Lainson, R. (2003) Transmissores de leishmaniose tegumentar americana. Flebotomíneos do Brasil (ed. by E.F. Rangel \& R. Lainson), pp. 291-310. Fiocruz, Rio de Janeiro.

Rosa, J.R., Salomon, O.D., Andrade Filho, J.D. et al. (2010) Phlebotomine sand flies (Diptera: Psychodidae) of the province of Chaco, Argentina. Neotropical Entomology, 39, 303-305 doi: S1519-566X2010000200024 [pii].

Rosa, J., Pereira, D.P., Brazil, R.P., Filho, J.D.A., Salomón, O. \& Szelag, E. (2012) Natural infection of cortelezzii complex (Diptera: Psychodidae: Phlebotominae) with Leishmania braziliensis in Chaco, Argentina. Acta Tropica, 123, 128-131. https://doi.org/10.1016/j .actatropica.2012.04.008.

Salomón, O.D., Sosa-Estani, S., Dri, L. et al. (2002) Leishmaniosis teguemtnaria en Las Lomitas, provincia de Formorsa, Argentina, 1992-2001. Medicina (Buenos Aires), 62, 562-568.

Salomón, O.D., Wilson, M.L., Munstermann, L.E. \& Travi, B.L. (2004) Spatial and temporal patterns of Phlebotomine sand flies
(Diptera: Psychodidae) in a cutaneous Leishmaniasis focus in Northern Argentina. Journal of Medical Entomology, 41, 33-39. https://doi .org/10.1603/0022-2585-41.1.33.

Salomón, O.D., Rosa, J.R., Stein, M. et al. (2008) Phlebotominae (Diptera: Psycodidae) fauna in the Chaco region and Cutaneous Leishmaniasis transmission patterns in Argentina. Memórias do Instituto Oswaldo Cruz, 103, 578-584. https://doi.org/10.1590/S007402762008000600011.

Salomón, O.D., Acardi, S.A., Liotta, D.J. et al. (2009) Epidemiological aspects of cutaneous leishmaniasis in the Iguazú falls area of Argentina. Acta Tropica, 109, 5-11. https://doi.org/10.1016/j .actatropica.2008.08.002.

Salomón, O.D., Rosa, J.R., Fabiani, M. et al. (2011) Distribucion de lutzomyia longipalpis en el chaco argentino, 2010. Medicina (Buenos Aires), 71, 225-230.

Saraiva, L., Filho, J.D.A., de Oliveira Silva, S., de Andrade, A.S.R. \& Melo, M.N. (2010) The molecular detection of different Leishmania species within sand flies from a cutaneous and visceral leishmaniasis sympatric area in Southeastern Brazil. Memorias do Instituto Oswaldo Cruz, 105, 1033-1039. https://doi.org/10.1590/S007402762010000800013.

Sudia, W.D. \& Chamberlain, R.W. (1962) Battery-operated light trap, an improved model. Mosquito News, 22, 126-129.

Szelag, E.A., Parras, M.A., Fabiani, M., Rosa, J.R. \& Salomón, O.D. (2014) Incipient colonisation of Lutzomyia Longipalpis in the city of Resistencia, province of Chaco, Argentina (2010-2012). Memórias do Instituto Oswaldo Cruz, 109, 488-491. https://doi.org/10.1590/00740276130054.

Szelag, E.A., Andrade De Filho, J.D., Rosa, J.R. et al. (2016) Argentinian phlebotomine fauna, new records of Phlebotominae (Diptera: Psychodidae) for the country and the province of Chaco. Zootaxa, 4139, 427-430. https://doi.org/10.11646/zootaxa.4139.3.8.

Accepted 2 November 2017 